\title{
Keeping Track of Assessment and Other Quality Control Data under EC2000
}

\author{
James Patton, PhD, PE \\ Electrical and Computer Engineering \\ University of Maine
}

\begin{abstract}
Recently, our department was reviewed under ABET's EC2000 criteria. We struggled to strike a balance between gathering sufficient statistics and assessment data, while trying to minimize the continuous administrative overhead of doing so. As a small department, we cannot afford to hire additional personnel to support EC2000. As a result, we created databases, perl scripts, web forms, and other supporting materials to minimize the bookkeeping associated with maintaining our quality control system. This paper describes the tools that were developed to gather assessment data, process the data, report the data, provide documentation of actions taken in response to the data, and ensure our criteria are being appropriately satisfied by the curriculum. These tools serve to automate the data processing as much as we think is feasible and appropriate.
\end{abstract}

\section{Introduction}

One of the challenges for small engineering departments implementing ABET EC2000 is finding the human resources to adequately administer and manage the associated record keeping. ${ }^{1}$ King and Schimmel discuss faculty motivation and the need to carefully control the amount of data collected $^{2}$. Schmahl et al discuss the need for careful organization of data ${ }^{3}$. Gassert et al emphasize that materials should be prepared in such a way to allow easy program review ${ }^{4}$.

We did not expect to receive additional funding to support additional administrative staff, so we developed a process where data gathering and record management were automated. We have extensively incorporated the web in our process. In fact, the Department now keeps the master copy of its most important operating documents (including our ABET report) on the web for all to view.

An important assumption we made in designing our quality control process was the conscious effort to avoid the creation of sub-committees to task with assignments related to ABET. As much as possible, we wanted to include the whole faculty in the process and reduce the amount of record keeping associated with sub-committee discussions/reporting.

Another important assumption was that, to the maximum extent possible, we would utilize existing methods of student assessment. In other words, we believed our own grading system could be used to assess and track student performance with some slight modifications. 


\section{ABET Process}

As a department, we've always believed we operated in the spirit of EC2000 - we just didn't implement the formal controls needed to ensure a continuous and consistent quality control process until EC2000. Using the tools we developed for EC2000, we began to see the actual procedures necessary to make the process tangible for our department. Defining the instruments to achieve quality control helps define the process itself. For example, Awoniyi proposes the use of a template approach where a department creates files and documents to fill it. ${ }^{5}$ The now familiar ABET "Two Loop Process" " is illustrated in Figure 1. The two-loop process is certainly open to interpretation, and we have no doubt that others will disagree with our particular interpretation. More importantly, it offers a guideline around which we can develop specific procedures and policies. Associated with each element of the process is a set of tools and supporting data or documents that illustrate just how the process is achieved.

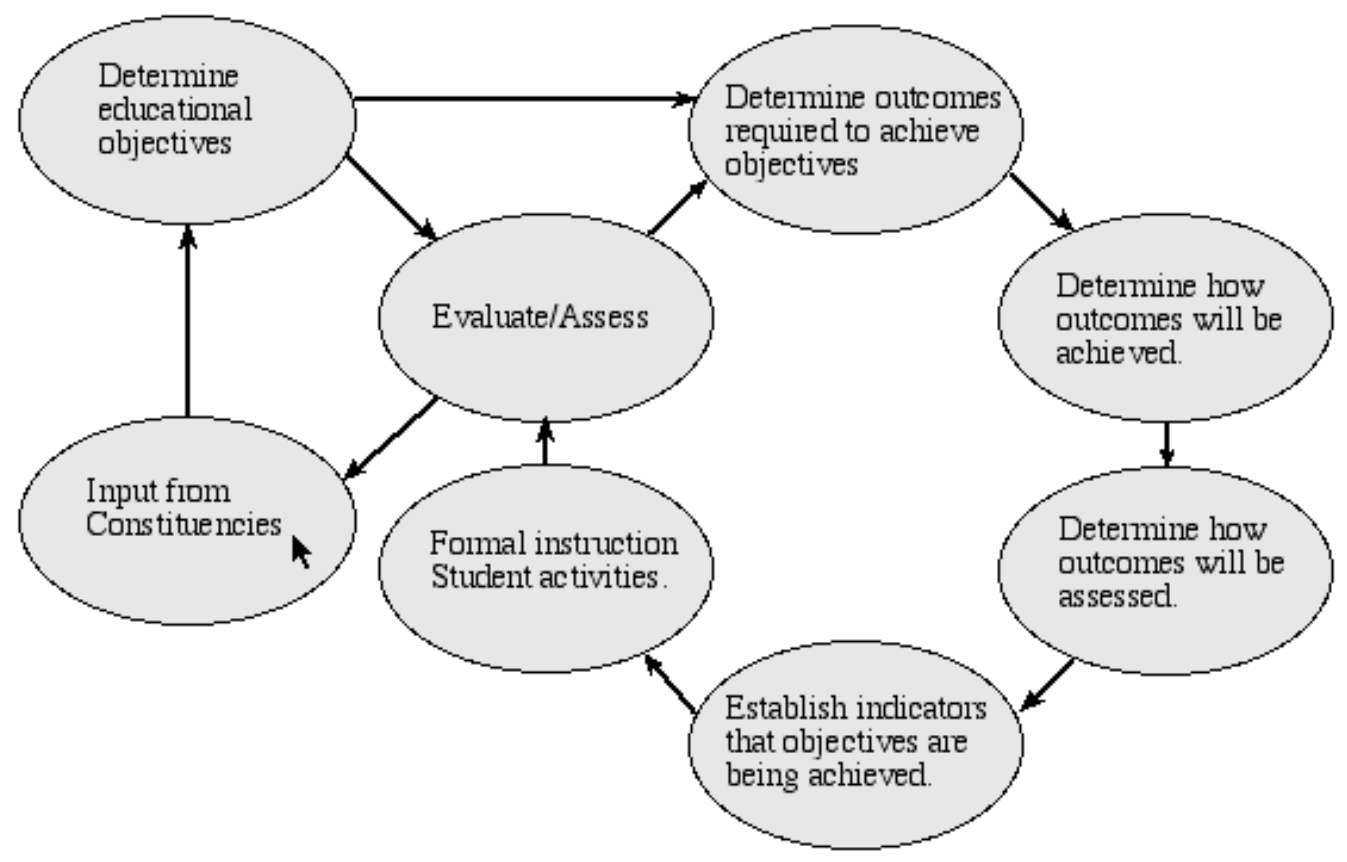

Figure 1 - The ABET Two Loop Process

\section{Tools to Support the ABET Process}

Table 1 shows the tools and supporting data necessary to implement the two-loop process. Where appropriate, this table and the descriptive text contains live links to our web site. If you are reading this paper on line, you should be able to click to the web pages directly. The links are also accessible from our ABET report at www.eece.maine.edu/abet/index.html. All data processing was achieved using cgi perl scripts written to allow complete specification of the data processing tasks within the html code of the calling web page. In other words, only a knowledge of html and the functionality of the perl scripts are needed to manipulate the data. No perl code is edited to manipulate data or files.

We will begin at the bottom of the loop because this step represented, for us, the most timeconsuming, and one of the most worthwhile tasks associated with EC2000. 
Establish indicators that objectives are being achieved - Faculty were asked to define the indicators that would tell them that the overall course and curricular objectives were being achieved. These indicators are the signs that students have mastered specific intellectual tasks required for a course. Specific exam or homework grades indicate mastery of these concepts. The concepts represent the specific course objectives and are quite detailed. Each specific course objective is mapped to the ABET "a-k" criteria in a database and on the web page. In this way, we immediately see which specific course objectives are contributing to the overall satisfaction of the "a-k" criteria. From the web page, we can sort the specific course objectives by course or by any of the criteria we define. We can sort the database to observe where in the entire curriculum we implement specific course objectives that contribute to any one of the ABET criteria. We note that Owen et al also describe a database approach for keeping track of program outcomes. $^{7}$

One of the most important benefits of this task is that we can now clearly see what concepts are taught in the prerequisites to any particular course, and we can discuss the detailed content of all required courses.

Maintenance of the database is achieved at the end of each semester when faculty submit a webbased GPA Indicator Report. They can submit changes to their specific course objectives by downloading a spreadsheet and editing it for the course they teach. It is then easily cut and pasted into the master database.

Formal instruction/student activities - Our assessment process is heavily dependent on the use of grades to determine student mastery of specific course objectives. Hence, it is important to establish evidence that indicates just what an A, B, C, D, or F means. The student activities that result from formal instruction represent student work that is collected and archived. It is possible to correlate the grades received with the actual student work for any course. In the past, we collected this evidence only in the year prior to the ABET visit. We now collect it routinely for every course. This evidence is examined if there is an anomaly in the statistics reported in the GPA Indicator Report from one year to another. This anomaly will be discovered in the data collected in preparation for the Visiting Committee meeting. Our industrial advisory committee, or Visiting Committee, meets annually in the fall.

Determine educational objectives - The primary means of documenting the discussion surrounding the establishment of Department-wide educational objectives takes place at everyother week staff meetings where minutes are recorded. The objectives are posted on our web page and modified as necessary. At its annual meeting, the Visiting Committee helps determine Department objectives. The Report from Visiting Committee is also posted to our web page.

Input from constituencies - comes from feedback from our Monthly Newsletter, Graduate Exit survey, Alumni/ae Survey, and student evaluation forms. The newsletter is a surprisingly effective source of feedback. Every month, we update our news page and email a brief "teaser" to approximately 700 future students, current students, former students, and friends of the department via a list serve. In the best spirit of media marketing, we try to induce email recipients to click on our news page. So far, we have far more people requesting to subscribe to the notification list serve than are "unsubscribing". We think the joke at the end of every newsletter helps. Once in a while, however, we sneak in an important question related to curriculum. After inserting one of these curriculum questions in a newsletter last year, we 
received nearly twenty opinions within two days. We have never received that kind of rapid constituent feedback before.

As much as possible, we try to email notification of web-based survey forms to graduating seniors and four-year/eight-year alumni/ae. When they respond via the web, their response is automatically mailed to the Chair, the Administrative Associate, and is appended to a delimited text file on our web server. We can import the text file into any spreadsheet or database program to further process it. The primary venue for presentation of this data is the annual Visiting Committee meeting.

Table 1 - Tools Supporting ABET Process

\begin{tabular}{|c|c|c|}
\hline Process element & Tools or Supporting data & Medium \\
\hline $\begin{array}{c}\text { Establish indicators that } \\
\text { objectives are being achieved }\end{array}$ & Specific course objectives & sortable web database \\
\hline Formal instruction/student activities & $\begin{array}{l}\text { Gathered tests, homework, lab reports, } \\
\text { project reports }\end{array}$ & paper \\
\hline \multirow{2}{*}{ Determine educational objectives } & Faculty meeting minutes & electronic text, web \\
\hline & Report from Visiting Committee & web \\
\hline \multirow{5}{*}{ Input from constituencies } & Monthly Newsletter & web. list serve \\
\hline & Graduate Exit survey & web form/database \\
\hline & Alumni/ae Survey & web form/database \\
\hline & Mid-semester Course Evaluation & web form/database \\
\hline & Semester-end Course Evaluation & bubble form \\
\hline \multirow{3}{*}{ Evaluate/Assess } & GPA Indicator Report & web form/database \\
\hline & Report from Visiting Committee & web \\
\hline & Graduation Check-off Sheets (ELE, CEN) & web \\
\hline \multirow{2}{*}{$\begin{array}{c}\text { Determine outcomes required to } \\
\text { achieve objectives }\end{array}$} & Faculty meeting minutes & electronic text, web \\
\hline & Report to Visiting Committee & password restricted web \\
\hline \multirow{4}{*}{$\begin{array}{l}\text { Determine how outcomes } \\
\text { will be achieved }\end{array}$} & GPA Indicator Report & web form/database \\
\hline & Faculty/Staff Annual Plans & electronic text \\
\hline & Curriculum Sheets (ELE, $\underline{\text { CEN) }}$ & web \\
\hline & Graduation Check-off Sheets (ELE, CEN) & web \\
\hline \multirow{2}{*}{$\begin{array}{l}\text { Determine how outcomes } \\
\text { will be assessed }\end{array}$} & Faculty meeting minutes & electronic text, web \\
\hline & Report from Visiting Committee & web \\
\hline
\end{tabular}

Similarly, we ask students to voluntarily submit "semi-anonymous Mid-semester Course Evaluation feedback via the web. It is "semi-anonymous" because the web master must confirm the entry to be non-bogus. Students are required to submit their name and email addresses, and a confirming email is returned to the student with their responses. After acceptance by the web master, a perl program strips the student's name and email address from the responses and compiles them for distribution to faculty. The mid-semester evaluation form encourages greater student comment feedback. This evaluation form is primarily for the benefit of faculty in improving their teaching methods and is put in their personnel file.

The Semester-end Course Evaluation is a traditional, anonymous, bubble sheet survey distributed and processed by the University. The results are placed in faculty personnel files for reappointment, tenure, or promotion purposes. 
Evaluate/Assess - On the GPA Indicator Report web form, we identify key components of required courses and track the grades received. For example, an electronics class might have a "lecture" component, a lab report component, and a lab performance component that are graded separately and tracked for ABET purposes because they relate to distinct "a-k" criteria. From year to year, we track the average grade and standard deviation. We also routinely gather sample student work for all our classes to ensure that grading standards do not change. If they do change, we want to know why.

At the end of each semester, faculty submit the GPA Indicator web form. The data is emailed to the Chair, and accumulated in a delimited text file. It is compiled and presented at the annual Visiting Committee meeting, where we observe trends in student performance in key courses or course components. The VC may suggest changes to the curriculum or comment on teaching methods in its report to the Department. Note that we do not track student performance in elective courses. These courses change sufficiently often that we determined it would be too difficult to maintain a consistent and believable track record.

The GPA Indicator form also gives faculty the opportunity to document changes made to the course objectives or procedures and allows them to offer their comments regarding the efficacy of their teaching methods, and the preparedness of the students in their courses.

Graduation check-off lists are also available from the web. The University is in the process of automating this degree-audit function. Hence, we have not attempted to program this assessment function.

Determine outcomes required to achieve objectives - This process takes place in faculty meetings and the Visiting Committee meeting based on data compiled from the various sources discussed. An example of this process is a recent curriculum decision to require a grade of $\mathrm{C}$ - or better for all prerequisites to ECE courses. This outcome was deemed necessary to ensure achievement of our educational objectives. Table 2 shows the reports that are prepared for the faculty and Visiting Committee to evaluate whether we are achieving our educational, as well as other Department, objectives.

Table 2 - Reports submitted annually to the Visiting Committee

\begin{tabular}{|l|}
\hline Instructor Evaluation of Required Undergraduate Courses (GPA Indicator) \\
\hline Instructor Evaluation of Required Undergraduate Courses - Comments \\
\hline Senior Exit Interview Data \\
\hline Senior Exit Interview Comments \\
\hline Enrollment Statistics \\
\hline Entering SAT Scores \\
\hline Degrees Awarded \\
\hline External Funding \\
\hline Grad Student Enrollment \\
\hline Web Page Visit Statistics \\
\hline
\end{tabular}


Determine how outcomes will be achieved - We examine this question on two levels: what changes are needed in specific courses and what general curricular changes are necessary?

In the first case, each semester, faculty submit specific, recommended changes to required courses on the GPA Indicator Report. In addition, all faculty submit planned changes to all courses (required and elective) in an annual plan. As part of the faculty member's annual plan, the faculty member is asked, "Are there any course changes you feel are necessary as a result of feedback from course evaluations?" Each faculty plan is distributed to all faculty to encourage informal discussion.

On the more general level, we maintain a recommended curriculum that is posted to the web and serves as the "master document". Because the curriculum is constantly modified, students are made aware that the most recent and accurate recommended curriculum is available on the web. The graduation check-off sheets (also available on the web) are the enforcement mechanism for the curriculum. While the recommended curriculum gives a recommended schedule for satisfying the curricular requirements, it is seldom strictly followed. The check-off sheets, however, represent the final check, made by faculty advisors, to ensure the curricular outcomes have been achieved.

Determine how outcomes will be assessed - With respect to curricular outcomes, the faculty are primarily responsible for designing the curriculum sheets, graduation check-off sheets, and GPA indicator reports. This process is documented in the faculty meeting minutes and the results are posted to the web. In addition, the Visiting Committee has input to this process.

Individual faculty determine how specific course outcomes (usually grades) will be assessed. An important check on this process is that the GPA Indicator Report asks faculty to comment on the preparation of students who received greater than a $\mathrm{C}$ - in a course prerequisite. These comments are used to alert faculty that the assessment of a particular prerequisite course is not accurately indicating achievement of specific course objectives.

\section{Conclusions}

Under EC2000, ABET has given a great deal of latitude to programs to define their own quality control processes. These processes can be extraordinarily complex. For small programs that do not have the resources to support devoted personnel to the ABET process, quality control is a substantial administrative and managerial challenge. Automated data collection and sorting helps relieve the burden. The internet is very beneficial in communicating the process to all constituencies.

We believe we have developed quality control processes and procedures that can be supported over the long-term and that will ultimately result in undergraduate programs and graduating engineers that best represent the University.

\section{References}

1. Sanoff, A.P., "Under the Magnifying Glass", ASEE Prism, October 2001, pp 37-38

2. King, F., Schimmel, K. "A Model for Faculty Involvement in Closing the Outcomes Assessment Loop", American Society of Engineering Education 2001 Annual Conference and Exposition, Paper \#689, Session 2793 
3. Schmahl, K., Ettouney, O.,Stenger, J., Moller, J., Noble, C., "Techniques for Assessment in a Successful ABET 2000 Accreditation Evaluation", American Society of Engineering Education 2000 Annual Conference and Exposition, Paper \#1803, Session 2263

4. Gassert, J., Petersen, O., Sebern, M. "A View of From Both Sides of Abet Criteria 2000; The Reviewed and the Reviewers", American Society of Engineering Education 2000 Annual Conference and Exposition, Paper \#1871, Session 2309

5. Awoniyi, S.A., "A template for Organizing Efforts to Satisfy ABET EC2000 Requirements", Journal of Engineering Education, Vol. 88, no. 4, 1999, pp.449-453.

6. ABET - Information for Programs and Institutions - www.abet.org/info_prgs_eac.html, www.abet.org/twoloops.html

7. Owen, C., Scales, K., Leonard, M., "Preparing for Accreditation Review Under ABET Engineering Criteria 2000: Creating a Database of Outcome Indicators for a Variety of Engineering Programs", Journal of Engineering Education, Vol. 88, no. 3, July 1999, pp.255-259.

\section{Biography}

Dr. Patton came to the University of Maine in 1991. He is currently Chair of the Electrical and Computer Engineering Department. Prior to joining UMaine, Dr. Patton worked for General Electric Co. and Systems Control Inc. He is a registered Professional Engineer in the State of Maine, a Senior Member of the IEEE, and is a member of Tau Beta Pi and Eta Kappa Nu. 